\title{
Trabalho Pedagógico na Escola: do que se fala?
}

Liliana Soares Ferreira'

'Universidade Federal de Santa Maria (UFSM), Santa Maria/RS - Brasil

RESUMO - Trabalho Pedagógico na Escola: do que se fala? ${ }^{1} \mathrm{O}$ artigo apresenta uma explicação para a categoria trabalho pedagógico, considerando-a fundamental na descrição de qual é e como acontece o trabalho dos professores, e resgata sentidos desse trabalho na escola. O estudo assentou-se em princípios da análise dialética, incluindo pesquisa bibliográfica e sistematização dos dados com análise de conteúdo e elaboração de argumentos. Partiu-se dos sentidos de trabalho pedagógico, distinguindo-os e mostrando preponderância em relação a sinônimos. Relacionou-se ao trabalho dos professores, apresentando modos discursivos com os quais é possível descrever concepções da categoria na escola. Sugere-se que trabalho pedagógico é trabalho dos professores quando, na escola, há espaços e tempos para a produção de conhecimento em movimentos dialéticos entre o projeto pedagógico individual dos professores e o projeto pedagógico institucional, constituindo a práxis pedagógica.

Palavras-chave: Trabalho Pedagógico. Escola. Trabalho dos Professores. Práxis Pedagógica.

ABSTRACT - Pedagogical Work in the School: what is it about? The article presents an explanation of the category pedagogical work, considering it as fundamental in the description of what and how are the teachers working, and recovers meanings of this work in school. The study was based on principles of dialectical analysis, including bibliographic research, systematization of the data through content analysis and elaboration of arguments. The meanings of pedagogical work were distinguished, and the preponderance regarding the synonymous was presented. Pedagogical work was related to the teachers work, through discursive methods with which it is possible to describe the conceptions of this category in school. The research suggests that pedagogical work is the teachers work when, in school, there are spaces and times to produce knowledge in dialectical movements between the teachers' individual education project and the institutional pedagogical project, which constitutes the pedagogical praxis. Keywords: Pedagogical Work. School. Teachers Work. Pedagogical Praxis.

Educação \& Realidade, Porto Alegre, v. 43, n. 2, p. 591-608, abr./jun. 2018. 591 http://dx.doi.org/10.1590/2175-623664319 
Trabalho Pedagógico na Escola

\section{Introdução}

Há algum tempo busca-se entender o sentido da categoria trabalho pedagógico nos discursos sobre educação. Já no início dos estudos, pensava-se que talvez houvesse desistência, pois uma categoria tão repetida cotidianamente já poderia, com tantas publicações na área da educação, ter sido exaustivamente explorada. Foi grande a surpresa ao se descobrir, com base de pesquisa em periódicos e eventos representativos da área da educação, que não havia substancial quantidade de estudos no sentido de esclarecer essa categoria, apresentar concepções ou mesmo explicá-la. Foram encontradas, analisando a literatura sobre o tema, duas genéricas maneiras de abordar esse conceito: a) desconsiderando-o e tornando-o irrelevante para as análises sobre educação e sobre o trabalho dos professores; b) naturalizando-o, como sinônimo de prática pedagógica, ação pedagógica, de didática ${ }^{2}$ ou de metodologia, sem apresentar conceitos.

A título de exemplificação, análises de comunicações em um importante evento, cuja temática central é o trabalho dos professores (seminários da Rede de Estudos sobre o Trabalho Docente - RedEstrado), entre 2008 e 2011, mostraram que a categoria trabalho pedagógico não tinha a relevância que a tornasse tema das comunicações e, quando aparecia, estava em posição de sinonímia com alguma outra categoria (Ferreira; Hypolito, 2013, p. 1). Naquela ocasião, foram estudados os sentidos de trabalho nos artigos apresentados no VII Seminário de La Red Latinoamericana de Estudos sobre Trabalho Docente (Buenos Aires, 2008) e no I Encontro Luso-Brasileiro sobre Trabalho Docente e VI Encontro Brasileiro da RedEstrado (Maceió e Alagoas, 2011).

Para este estudo, foram selecionados textos que continham referências ao tema trabalho no título, com especial atenção para o subtema trabalho dos professores. Analisou-se, tendo como metodologia a Análise de Conteúdo (Bardin, 2011), em primeira fase, cerca de três centenas de textos que atenderam a esse critério. Após, passou-se às fases de análise dos descritores e categorização, reduzindo, então, a quantidade para trinta e oito produções. Foram lidos novamente os textos e destacados trechos que continham referências às categorias com os quais se passou a trabalhar. Um dos aspectos resultantes das análises é relativo à necessidade de aprofundamento do estudo sobre o trabalho dos professores, tendo a escola como contexto. Percebeu-se também que as expressões trabalho docente, trabalho pedagógico e trabalho dos professores, muitas vezes, são apresentadas como sinônimas, gerando imprecisões que obstaculizam a produção de sentidos sobre o tema em análise.

Sem concordar com essas maneiras de tratar tão importante categoria, a partir dessa constatação, tem-se envidado esforços no sentido de elaborar um modo de explicar e entender trabalho pedagógico supondo-o como singular e fundamental na explicação, não somente de qual é e como acontece o trabalho dos professores, mas também resgatando sentidos desse trabalho específico. Vale dizer, contrariamente 
a quaisquer descasos ou imprecisões, quando o tema é trabalho pedagógico, reitera-se:

[...] é a categoria central tanto na organização da escola, expresso em seu projeto pedagógico, quanto no conhecimento resultante dos processos realizados na instituição. Daí porque urge aprofundar a compreensão dessa categoria, estabelecendo mais claramente suas características e, sobretudo, implicações (Frizzo; Ribas; Ferreira, 2013, p. 563).

Este artigo expõe argumentos elaborados pelos estudos sobre o tema, na tentativa de contribuir com elementos que possam favorecer uma conceituação mais completa dessa categoria. Tais estudos, assentados em princípios da análise dialética, desenvolveram-se ao longo da última década e incluíram pesquisa bibliográfica, sistematização de dados produzidos com análise de conteúdo (Bardin, 2011) e elaboração de argumentos que compõem esse artigo. Refere-se à expressão análise dialética, revelando acreditar que engloba o método e o pensamento dialético. Com tal opção pela análise dialética, intenciona-se entender os movimentos entre o geral e o particular, entre causas e efeitos, destacando considerações e sistematizações relativas à problematização elaborada e, sobre ela, apresentando alternativas e possibilidades. Portanto, foi além da produção de dados durante a pesquisa bibliográfica, realizando um amplo estudo dos dados, entendendo-os como evidências de sentidos, comparando-os, analisando-os, articulando-os.

Como atividade análoga, sistematizou-se entrevistas com vinte e cinco professores que trabalham em escolas públicas de educação básica, localizadas na Região Central do Estado do Rio Grande do Sul, durante o desenvolvimento de projeto de pesquisa cujo objetivo foi conhecer os sentidos atribuídos ao trabalho e a si, como trabalhadores. Essa sistematização amalgamou-se a este estudo, permitindo a elaboração de modos discursivos apresentados na seção O Trabalho Pedagógico Por Dentro.

Na análise dos dados, realizou-se: a) leitura e releitura do material com o intuito de conhecer os dados e, posteriormente, elaborar hipóteses relacionadas às compreensões prévias do fenômeno estudado; b) elaboração de hipóteses que foram confirmadas ou refutadas com base na análise reiterada do material produzido; c) comparação entre as hipóteses e os índices encontrados no material; d) exploração dos dados, dando-lhes um tratamento com base em índices que facilitassem a análise categorial; e) categorização, ou seja, a relação entre as categorias elaboradas previamente e os índices encontrados, ampliando aquelas e redimensionando estas: "A análise categorial pretende tomar em consideração a totalidade de um texto, passando-o pelo crivo da classificação e do recenseamento, segundo a frequência de presença (ou ausência) de itens de sentido" (Bardin, 2011, p. 36). Para tanto, partiu-se dos sentidos já elaborados de trabalho pedagógico, distinguindo-o e mostrando a preponderância em relação a outras categorias encontradas como sinônimos. A seguir, relaciona-se essa categoria ao trabalho 
dos professores. Por fim, são apresentadas compreensões de trabalho pedagógico na escola.

Para encaminhar a argumentação, considera-se como suposto que todo trabalho pedagógico evidencia determinações que o organizam, compostas por crenças, escolhas, classificações e que, em conjunto, revelam tendências pedagógicas às quais se filia o trabalhador. No caso específico da educação, em especial da educação escolar, os trabalhadores são os professores, e seu trabalho pedagógico se organiza e reverbera no cotidiano escolar. Esse é o recorte com o qual se trabalhará: o professor como trabalhadori; seu trabalho como pedagógico; a escola como um tempo e um lugar cotidiano desse trabalho.

\section{Trabalho Pedagógico}

Como se pode descrever trabalho pedagógico? Tem-se optado por apresentar concepções em etapas, na seguinte sequência: descrição de trabalho, de pedagógico e, por fim, de trabalho pedagógico. Nessa perspectiva, tem-se proposto a entendê-lo como sendo o trabalho dos professores na escola, portanto, práxis pedagógica, uma práxis criadora, que tem as seguintes características: "[...] produção ou autocriação do próprio homem [...] é determinante, já que é exatamente ela que lhe permite enfrentar novas necessidades, novas situações. O homem é o ser que tem de estar inventando ou criando constantemente novas soluções" (Vázquez, 1977, p. 247).

Detalhadamente, estabeleceu-se que trabalho pedagógico seria a produção do conhecimento em aula, tanto dos professores, quanto dos estudantes. Mas vai além. Considera-se, ainda, que a produção do conhecimento pressupõe envolvimento e participação política em todos os momentos escolares, além de intenso imbricamento, comprometimento e responsabilidade com o projeto pedagógico institucional. Trata-se, pois, de um movimento dialético entre o individual e o coletivo: entre o que os professores concebem seu projeto pedagógico individual, e o que a escola, comunidade articulada, estabeleceu em seu projeto pedagógico institucional em consonância com o contexto histórico, social, político, econômico.

O trabalho pedagógico, portanto, é uma prática social munida de forma e conteúdo, expressando dentro das suas possibilidades objetivas as determinações políticas e ideológicas dominantes em uma sociedade ou, ainda, busca a explicitação da superação destas determinações. A escola, compreendida como o espaço institucional da formação no sistema do capital, cumpre determinações da prática social em que a organização do trabalho pedagógico procura dar conta dessa tarefa. (Frizzo; Ribas; Ferreira, 2013, p. 556).

Mais recentemente formulou-se que trabalho pedagógico é o trabalho dos professores, envolvendo a soma de escolhas que nem sempre são objeto de reflexão, por falta de tempo e de espaço na escola e fora 
dela, para que os professores possam refletir sobre o que realizam. Este trabalho, por sua natureza, está relacionado a como o grupo que compõe a escola se organiza, como entende e produz educação. Transita entre o individual e o coletivo, de modo dialético, elaborando e acontecendo cotidianamente na escola (Ferreira, 2017).

Apesar do esforço acadêmico até aqui, entende-se que há muito a realizar ainda para ampliar e tornar mais clara essa elaboração. Considera-se que o trabalho pedagógico é trabalho. Trabalho é uma manifestação humana à medida que põe o humano em movimento de modo planejado e sistemático e, ao fazê-lo, produz historicidade e constitui-se esse humano, distinguindo-o dos demais seres vivos. Essa é uma concepção que não exclui aspectos como a comunicação, a linguagem, a relação com os outros; a concepção do social, ao contrário, inclui e permite que se entenda não somente o trabalho, mas a vida humana ${ }^{4}$. Tendo por base essa concepção geral, trabalho pedagógico é o trabalho de sujeitos que, ao realizá-lo, produzem historicidade e se autoproduzem. Objetiva elaborar meios para alcançar um fim, mas vai além: põe em interação, inter-relação, relação (esses termos não se substituem, por isso são citados) os sujeitos, com seus saberes, de modo sistemático, dialógico, produzindo conhecimentos a partir da interlocução acerca desses saberes. É um trabalho imaterial, por gerar bens imateriais relativos à criação de informações ou modos de divulgar e criar essas informações, de argumentos, de ideias, etc. É considerado, também, na perspectiva marxiana, como trabalho improdutivo, pois não contribui diretamente para o aumento da mais-valia. Mais-valia, explicada por Marx, "[...] se origina de um excedente quantitativo de trabalho, da duração prolongada do mesmo processo de trabalho" (Marx, 2008, p. 231). Tal conceito de mais-valia é diretamente relacionado ao conceito de tempo:

A magnitude absoluta do tempo de trabalho - o dia de trabalho, a jornada de trabalho - é constituída pela soma de trabalho necessário e do trabalho excedente, ou seja, do tempo em que o trabalhador reproduz o valor de sua força de trabalho e do tempo em que produz a mais-valia (Marx, 2008, p. 266).

Além disso, está localizado na área dos serviços, ou seja, um trabalho que atende a um objetivo de prestar, mediante contrato, uma tarefa. Do mesmo modo, é considerado como um serviço atinente ao campo educacional. Assim, quaisquer propostas de delineamento de uma concepção de trabalho pedagógico estão relacionadas a essas três dimensões: o resultado que produz, a sua caracterização como serviço e o campo onde se insere. Portanto, cada uma dessas dimensões será abordada, compondo um campo teórico-semântico, cujo objetivo central é apresentar uma concepção mais completa de trabalho pedagógico.

Todo o trabalho objetiva um resultado, um fim, um produto. Por isto se trabalha: para realizar algo que, antes do trabalho, não existia. Por esse motivo, conserta-se, constrói-se, negocia-se algo. Faz-se por- 
que há uma necessidade que, depois de realizada, resulta um produto configurado. No caso do pedagógico, o que resulta do trabalho é a produção do conhecimento. Por produção do conhecimento, entende-se a apropriação individual de um saber. De certo modo, recorre-se a Vigotski (1996) ao fazer esta afirmação. Todas as pessoas trazem consigo saberes, oriundos de sua historicidade, de sua cultura, de sua vida, enfim. Ao interagirem em aula por meio da linguagem, apropriam-se dos saberes, tornando-os conhecimentos por complexos processos cognitivos, porque, de alguma forma, havia uma demanda de conhecer. Produzir, então, não quer dizer inventar o conhecimento, mas torná-lo seu, conhecer. Para tanto, organiza-se uma situação de aula, para a qual convergem sujeitos, cada um com seus saberes, que passam a interagir por meio da linguagem. Aula, aqui, é entendida no seu sentido mais amplo: todo o momento de sistemática produção do conhecimento. Resulta a socialização desses saberes que, pela interlocução, se estabilizam como conhecimento.

[...] interlocução implica conversação entre duas ou mais pessoas, duas ou mais instituições, dois ou mais grupos. Este 'dois ou mais' contém o diverso e o múltiplo. Este "dois ou mais" pode-se tornar-se muitos mais, com o que se transversalizam uma diversidade de interesses, intensidades e direcionalidades da interlocução, com isto se altera a condição de ouvir e dialogar com os interlocutores (Werle, 2012, p. 424).

Nesse sentido, o trabalho pedagógico é um trabalho imaterial e não é somente "[...] trabalho em serviços propriamente ditos, mas também trabalho reflexivo inserido no processo de produção de mercadorias ou no trabalho industrial que se utiliza de tais atributos da comunicação e da inteligência” (Alves, 1999, p. 5). Isso acontece com frequência em todo trabalho de produção coletivizado os quais exijam "[...] apropriação dos atributos de comunicação e inteligência para sustentação de seus dispositivos organizacionais (just-in-time/kanban, kaizen, etc.)" (Alves, 1999, p. 5). Por isso, é descrito como contraposto ao trabalho produtivo, configurando-se em trabalho que não produz valor, mas garante o movimento mais rápido do valor:

São atividades vinculadas, em sua maioria, aos serviços e dentro desses à utilização da capacidade intelectual do coletivo de trabalhadores. Trata-se de um conceito figurativo, metafórico que Marx usou em determinados momentos de sua análise do capitalismo para ilustrar relações mercadológicas de transição (entre a produção e a circulação) que não compreenderiam particularmente o 'espírito do capitalismo', mas que, nem por isso, deixariam de ser controladas pelas relações sociais fundamentais que as orientam na direção da extração de mais-valia (Amorin, 2006, p. 2).

Tem valor de troca na medida em que é um trabalho que movimenta e organiza todas as demais esferas da produção, e valor de uso 
porque é condição, sobretudo na contemporaneidade, para que as demais mercadorias se expandam em seus valores. Nessa perspectiva, a produção do trabalho imaterial é consequência das propriedades cognitivas, afetivas, de mobilização de dados e informações do próprio trabalhador (Grisci, 2006). Portanto, vai além da materialidade: "A condição do trabalho imaterial é a produção de subjetividade, o conteúdo do trabalho imaterial é a produção de subjetividade, o resultado do trabalho imaterial é a produção de subjetividade” (Pelbart, p. 37, 2000).

Referente à caracterização do trabalho pedagógico como improdutivo, reafirma-se que esse trabalho não está diretamente relacionado à produção e à acumulação de capital. Nesse sentido, faz-se referência ao que afirma Marx: "[...] somente é produtivo o trabalho que produz capital; que, consequentemente, o trabalho que não o faz, por mais útil que possa ser - pode muito bem ser nocivo -, não é produtivo para a capitalização, logo, é trabalho improdutivo" (Marx, 2011, p. 377). E o autor, na mesma obra, ainda esclarece:

\begin{abstract}
O próprio trabalho só é produtivo quando incorporado ao capital, ali onde o capital constitui o fundamento da produção e o capitalista, portanto, é o comandante-em-chefe da produção. A produtividade do trabalho devém força produtiva do capital, da mesma forma que o valor de troca universal das mercadorias se fixa no dinheiro. O trabalho, tal como existe para si no trabalhador em oposição ao capital, o trabalho, portanto, em sua existência imediata, separado do capital, não é produtivo (Marx, 2011, p. 382).
\end{abstract}

Nessa perspectiva, o trabalho pedagógico não está imediatamente ligado ao capital. Ainda assim, por sua natureza, contribui com o capital, na medida em que educa os trabalhadores. Estes, na lógica capitalista, serão a força de trabalho, um pressuposto para a produção. Os professores, então, são trabalhadores pedagógicos, cujo trabalho produz outros trabalhadores. Tais características exigem que se pense no alerta de Saviani (1984, p. 81): "Na escola, espaço e tempo do pedagógico, o que é produto não está indissociado da ação de produzir". Essa indissociação contribui para que se imprecise a concepção de trabalho pedagógico como trabalho dentro da sociedade capitalista. Entretanto, trata-se de um investimento nos sujeitos, nas suas condições, no seu modo de entender o mundo e, a partir disso, estabelecer-se.

Como serviço, o trabalho pedagógico está incluído no rol de atividades humanas, nas quais uma força de trabalho está disponível para realizar uma tarefa para a qual foi previamente contratada. Parece um tanto frio descrever assim o trabalho pedagógico, entretanto, há que se considerar as relações sociais capitalistas no entorno, que convergem para essa configuração. Isso não exclui o fato de ser um serviço no qual os seres humanos se implicam subjetivamente e, assim, convivem. Somente considerar essa implicação parece colocar em relevo o subjetivo em detrimento da objetividade das relações sociais que organizam o trabalho pedagógico como atividade imanentemente social. A questão também não é privilegiar a objetificação em detrimento da subjetivida- 
de, pois não se trata de uma exclusão, mas entender como se articula o trabalho pedagógico como serviço.

Quanto ao campo, o trabalho pedagógico inclui-se no campo intelectual. Entende-se campo, na perspectiva de Bourdieu, como um todo no qual as partes se inter-relacionam de modo a compor um sistema em que há contradições e relações que põem em movimento essas partes (Bourdieu, 2012). Ao se destacar tal critério, estabelece-se uma localização que possibilite a classificação desse trabalho - classificar no intuito de estabelecer uma referência, no caso, a de que o trabalho pedagógico está relacionado a um conjunto maior de relações com o qual se coaduna, a ponto de estabelecer suas características, como no caso desse tipo de trabalho e o social capitalista (o conjunto maior) representado pela escola. Da relação entre eles se pode descrever o primeiro e esclarecer imprecisões que, como mencionado, rondam o conceito de trabalho pedagógico.

Uma vez caracterizados esses três aspectos (trabalho pedagógico visa à produção do conhecimento, catalogado na área de serviços e incluído no campo intelectual), espera-se ter criado um contexto teórico-semântico, com características sociais, históricas e filosóficas, com base no qual se apresentará uma concepção de trabalho pedagógico. A seguir, descreve-se o trabalho pedagógico por dentro, visto a partir dos sujeitos que tradicionalmente são os trabalhadores pedagógicos. Para tanto, reitera-se que o trabalho dos professores é trabalho pedagógico.

\section{O Trabalho Pedagógico Por Dentro}

Considera-se os professores sujeitos de seu trabalho, mas cabe esclarecer: parece um tanto antiquado ou mesmo paradoxal falar em professores sujeitos. Antiquado, se for considerada a vasta produção sobre o tema, ou negando a possibilidade de serem sujeitos ou reafirmando. Basta lembrar as discussões sobre a desprofissionalização dos professores, para exemplificar o primeiro grupo de produção, e as discussões sobre os professores como pesquisadores, para exemplificar os segundos. Entretanto, para fins do que se propõe neste artigo, é importante começar pela reafirmação dos professores como sujeitos. Tal afirmação torna implícita, de modo muito simples, a compreensão de que, por serem cidadãos capacitados a articularem sentidos e interações por meio da linguagem, dotados de potencialidade para construção de sua historicidade e agirem com base nos aspectos descritos na seção anterior, por si somente, apresentam-se como sujeitos. A compreensão de cidadão diz respeito a pertencer ao social, participar dele com direito a voto e contribuir politicamente. Obviamente, as limitações e possibilidades dessa vivência como sujeitos estão relacionadas à imersão em um mundo com características sociais bem específicas, o capitalismo. Nesse contexto, os professores e seu trabalho, assim como os demais trabalhadores, estão submersos em condições que lhes expõem à precarização, à fragmentação, à intensificação ${ }^{5} \mathrm{e}$, não raro, à desistência de trabalhar como professores. 
Em meio a esses processos, a escola, lugar onde majoritariamente acontece esse trabalho, adota a conformação correspondente ao entorno social. Se o capitalismo, em seu atual estágio exige concorrência desenfreada para justificar-se como instituição responsável (assim, parece supor) pelo conhecimento acumulado pela humanidade, a escola intenciona assemelhar-se cada vez mais às instituições sociais tradicionais: família, Igreja, sindicatos. É uma maneira de demonstrar priorização dos valores tradicionais. Ao assemelhar-se, assume o lugar de responsável por processos que denomina socialização - inclusão digital -, chegando a responsabilizar-se por cuidados com saúde, emprego e religião. Concomitantemente, a escola parece ter dificuldades em elaborar discursos que justifiquem sua existência: a) não é mais a única instituição social responsável pelo conhecimento e pelo conhecer; b) não tem condições de garantir ao estudante que, após o período de escolarização, sua vida será melhor e que obterá um emprego digno; c) submete-se a políticas educacionais que, em muitas situações, acabam por desestabilizar os professores, desmantelar o projeto pedagógico, em alguns casos, construído coletivamente, causando um estranhamento entre os sujeitos e os aspectos institucionais; d) cada vez mais, deixa de ser, com exceção de pequenas comunidades, o lugar social do encontro entre os sujeitos, sendo substituída por locais mais atraentes, como os shoppings centers, os clubes privados, as sedes de bairros, entre outros. É nesse tempo e ambiente, aqui genericamente configurado, que acontece o trabalho dos professores sobre o qual se fará referência.

Essa exposição inicial visa a apresentar o cenário a partir do qual será desenvolvida a argumentação sobre modos discursivos que descrevem o trabalho pedagógico desenvolvido pelos professores. Como suposto, discurso é toda a elaboração que responde à necessidade de apropriação e representação do que se vive. Não é um conceito elaborado com base em uma área do conhecimento específica, mas uma sistematização elaborada tendo por base o que se observa.

Também para fins da argumentação ora desenvolvida, diferencia-se trabalho e emprego. A diferenciação certamente não é excludente, apenas objetiva distinguir. Trabalho, na perspectiva desenvolvida por Marx (2008), é todo processo demasiadamente social, por meio do qual acontece a produção e a autoprodução humana. Já o emprego, a aplicação burocratizada do trabalho, é de ordem da pertença ao social, da necessidade de sobreviver obtendo recursos econômicos com a venda da força de trabalho.

Objetiva-se descrever quatro modos discursivos organizados a partir de quatro elementos: a) S1: o sujeito professor trabalhador; b) S2: o sujeito professor empregado; c) TP1: o trabalho pedagógico resultante do trabalho; d) TP2: o trabalho pedagógico resultante do emprego. Esses elementos são distintos, embora estejam, na realidade da escola, imbricados, amalgamados. A distinção possibilita a argumentação. Há ainda um quinto elemento, a linguagem, não descrita nos modos discursivos, exatamente porque é imprescindível, fazendo-se presente independentemente de ser nomeada. Desse modo, pretende-se aprofun- 
dar a concepção de trabalho pedagógico. Em sequência, são descritos esses modos discursivos que permitem descrever uma compreensão de como os professores se relacionam com o trabalho pedagógico que realizam. Pode-se, portanto, deduzir uma concepção ampliada do trabalho pedagógico escolar.

a) $\mathrm{S} 1 \leftrightarrow \mathrm{TP} 1$

Nesse modo de descrever discursivamente o trabalho pedagógico, tem-se os professores como trabalhadores, ou seja, como alguém que, transcendendo o imaginário de ser um missionado, um vocacionado, escolhido para uma função social, é entendido como participante de um grupo social que possui uma força de trabalho e a vende em troca de um salário. Tal força de trabalho inclui os conhecimentos da ciência que pratica, os conhecimentos acerca de como o ser humano aprende, os conhecimentos acerca de como se produz conhecimento. Nesse sentido, a concepção de trabalho pedagógico parte de uma perspectiva de

[...] ciência entendida como um produto social histórico, um fenômeno em contínua evolução, incluída no movimento das formações sociais e determinadas pelos interesses e conflitos sociais na qual se produz. O critério de cientificidade se materializa na prática histórica, a explicação e a compreensão do objeto se obtêm na medida em que recuperamos sua gênese e seu desenvolvimento, onde os fenômenos se explicam pela história dos próprios fenômenos. A relação entre sujeito e objeto é definida como concreticidade que se constrói como síntese da relação entre sujeito-objeto (Frizzo, 2008, p. 24).

Amalgamando esses conhecimentos, os professores têm condições de efetuar seu trabalho: a aula - e nela, o conhecimento.

b) $\mathrm{S} 2 \leftrightarrow \mathrm{TP} 1$

Descreve uma situação muito recorrente, que aponta o trabalho pedagógico imerso em condições minimizadoras de sua potencialidade em uma escola e em um contexto educacional que não são prioridade políticas. Nessa situação, tal representação apresenta professores que, apesar de se sentirem empregados, muitas vezes em condições de precarização, intensificação e fragmentação do que fazem, ainda assim realizam um trabalho pedagógico por excelência, transgredindo os dissabores do emprego.

c) $\mathrm{S} 1 \leftrightarrow \mathrm{TP} 2$

Esta outra situação retrata os professores que sabem sobre sua condição de pertença à profissão, sabem-se professores, mas por motivos relacionados a diversos fatores - descontentamento com as condições de trabalho, influência de um grupo que lhes convoca a agir de modo conformado, falta de tempo e condições para pensar acerca do que faz, entre muitas outras razões -, acabam realizando tarefas desconectadas, sem revelarem a existência de um projeto pedagógico seu, autônomo e responsável.

600 Educação \& Realidade, Porto Alegre, v. 43, n. 2, p. 591-608, abr./jun. 2018. 
d) $\mathrm{S} 2 \leftrightarrow \mathrm{TP} 2$

Os professores, nesse modo discursivo, produzem o trabalho pedagógico, entretanto, o fazem na condição de empregados, ou seja, de trabalhadores que cumprem as relações contratuais, sem necessariamente viver o trabalho em toda a sua intensidade. Surge, na perspectiva dos empregadores, dos que pagam os salários aos empregados, a noção de bom professor, aquele cumpridor de todas as exigências contratuais com algum mérito. O trabalho, por sua vez, acontece de modo quase mecânico, sem a inteira implicação dos professores.

Dada a sua recorrência, essa modalidade de descrição merece uma análise mais detalhada. Se o trabalho é humanizador, cumprir simplesmente o emprego é a modalidade mais alienadora dos sujeitos. É quando o ser humano abdica de sua humanização e entrega-se ao trabalho como algo a lhe oprimir: "O homem, por natureza livre e consciente, passa a ser apenas uma coisa que trabalha e aceita o trabalho para subsistir, como parte da sua natureza humana, sob uma falsa consciência. Na realidade, ele se desominiza" (Basbaum, 1977, p. 19). Os ideais de solidariedade e de liberdade, para esses sujeitos assim organizados, se obliteram. Sentem sobre si o peso de viver em uma sociedade dividida em classes, na qual lhes é subtraído o direito de ser sujeito de si e do seu trabalho. No caso específico dos professores, os processos de intensificação e precarização de seu trabalho se apresentam como elementos que complexificam suas condições de vida. Basbaum (1977, p. 24) descreve essa complexificação ao se referir aos trabalhadores de modo geral, mas, sem dúvidas, atinge os professores:

Quando o homem se vê forçado, desde o aparecimento da propriedade privada, a trabalhar para sobreviver, ou seja, vender sua força de trabalho, isso não significa que dedica apenas 8 ou 10 horas de trabalho a outro. Na realidade lhe entrega quase tudo. Às 8 ou 10 horas de trabalho que gasta, no local em que exerce sua atividade, é preciso juntar as horas que consome desde o levantar até chegar ao local e mais outras tantas, do local de trabalho até a volta ao lar. Como suas noites devem ser bem dormidas, para que possa no dia seguinte vender sua força de trabalho, sua hora de dormir está condicionada ao fato de que deve dormir cedo. Toda sua vida familiar (da alimentação ao sono) passa a girar na realidade em torno dessas 8 ou 10 horas que vende ao patrão, o que significa praticamente as 24 horas do dia.

Cabe destacar ainda que os professores levam para casa atividades: correções, planejamentos, revisões, estudos. Tais atividades, que deveriam ser realizadas no local de trabalho, são realizadas em casa, dado o fato de que naquele local esses profissionais estão envolvidos com os estudantes, com os pais, com as rotinas, com as reuniões. Tudo isso caracteriza o trabalho pedagógico que realizam.

Esses modos discursivos descrevem quatro situações combinadas de trabalho pedagógico, as mais encontradas nas escolas cotidia- 
Trabalho Pedagógico na Escola

namente. Muitas vezes, em uma escola, pode-se encontrar uma, duas ou todas as situações, pois dizem respeito ao movimento do sujeito individual e dos instituídos coletivos, que se embatem ou simplesmente convivem. Todos os modos revelam a aderência entre os trabalhadores e as concepções e condições com as quais trabalham. Dessas situações, decorrem as características do trabalho pedagógico que realizam.

\section{O Trabalho dos Professores na Escola como Trabalho Pedagógico}

Por ser pedagógico, o trabalho dos professores reveste-se de uma intencionalidade, portanto, é político por excelência. Frisa-se a crença de que somente é pedagógico por resultar de um projeto próprio, que articula crenças, experiências, fazeres selecionados pelo sujeito. Denomina-se essa elaboração de projeto pedagógico individual, mas entende-se ser dialeticamente construído entre o individual e o coletivo, referendando-se e consubstanciando-se coletivamente. Por assim ser, a originalidade desse projeto é relativa; uma vez que resulta de uma historicidade, é substrato cultural, porém, é assumida por um sujeito em meio ao grupo também historicamente construído e cujo trabalho se produzirá no entremeio de suas crenças e a com-vivência. Portanto, a originalidade está nas escolhas reiteradamente realizadas. Daí seu caráter eminentemente político.

A consonância do pedagógico com uma realidade o faz assumir diferentes conformações, não havendo uma única concepção de pedagógico e, muito menos, de trabalho dos professores. Há, na verdade, várias tendências pedagógicas convivendo, inclusive, em um mesmo ambiente escolar. Explica-se tendência como sendo uma orientação, uma inclinação, ainda que não aprofundada, por determinadas crenças ou ações pedagógicas. Por esse motivo, são provisórias e podem se alterar conforme o tempo e o espaço escolar. Talvez isso justifique por que um mesmo sujeito possa trabalhar como professor em duas escolas diferentes e realizar dois trabalhos pedagógicos diferentes também, pois necessita coadunar seu projeto pedagógico individual com o projeto pedagógico escolar.

A elaboração de um projeto pedagógico individual exige que os professores selecionem suas interlocuções teóricas, estabeleçam referências com as quais poderão atribuir sentidos, elaborar interpretações do que vivem, inserindo-se em uma tendência e propondo seu trabalho pedagógico. Vale dizer: aos professores cabe analisar informações e teorias, construir um todo de conhecimentos sólidos para fundamentar seu trabalho. Analisando como se manifestam os projetos pedagógicos dos professores, pode-se reconhecer como se organiza seu trabalho, conhecendo também as tendências consciente ou inconscientemente reveladas por meio da linguagem, podendo compreendê-los em seu momento e nas configurações históricas que os caracterizaram.

Entende-se que pedagógico é, via de regra, uma decorrência de Pedagogia. Assim, cabe esclarecer também o entendimento de Pedago- 
gia para continuidade da argumentação. Em todo o lugar onde houver convivência e interação entre sujeitos, estão sendo elaborados saberes. Entretanto, historicamente, coube à escola ser o lugar onde esses saberes, socializados e em interação, na mediação pedagógica em que se configura a aula, produzem-se como conhecimento. Nessa perspectiva, a Pedagogia é uma forma de compreender a educação para além das paredes do prédio escolar, e o aprender é um processo que acontece sob a forma de relações em espaços diferentes, nos quais o sujeito estabelece conexões entre sua subjetividade e o ambiente, produzindo, assim, conhecimentos com base nesses saberes. A Pedagogia, portanto, não é somente uma possibilidade de reflexão acerca do processo educativo nas suas dimensões sociais, históricas, filosóficas e instrumentais. Ademais, não é um método, porque vai além dele, contextualizando-o e teorizando-o:

[...] Do mesmo modo que a educação não pode ser compreendida como objeto em si, a pedagogia não pode ser entendida como método para si, pois, como prática humana, a educação necessita da pedagogia como teoria que a determina para que possa se realizar como práxis humana, e a pedagogia como teoria da práxis educativa jamais pode bastar-se a si mesma, por precisar esclarecer e conduzir a educação como práxis humana, colocando-se desta forma no primado da prática (Schmied-Kowarzik, 1988, p. 128)

Assim, pode-se descrever a Pedagogia como uma práxis, cujas dimensões são sociais e educativas. Social, na medida em que surge do coletivo e a ele é remetida, de modo a contribuir na formação e autoformação humana. Educativa porque a Pedagogia é ciência da educação.

Pedagogia e práxis educativa são semelhantes a política e práxis social - ambas com tarefas próprias porém referentes umas às outras -, ambas determináveis uma a partir da outra e uma voltada para a outra unicamente como momentos da experiência dialética global da autodeterminação e da auto-realização humanas. Somente na medida em que a pedagogia tem êxito em se fundamentar a si mesma, em sua relação com a educação, como ciência prática da e para a educação, vinculando-se junto com a educação tanto teórica como praticamente à experiência dialética global da humanização, ela é capaz de se determinar e realizar dialeticamente como pedagogia dialética (Schmied-Kowarzik, 1988, p. 128).

Desse modo, por ser pedagógico, o trabalho acontece em meio a relações de poderes, dinamicamente imbricados, sugerindo, em alguns casos, conflitos e dissonâncias. Superar os conflitos no cotidiano, buscando entender e contribuir na dissolução dos poderes que impedem o grupo de realizar seu trabalho é agir politicamente.

Cabe ainda distinguir trabalho pedagógico e fazer pedagógico. Dalbosco (2007, p. 57) afirma que fazer pedagógico, determinado por ele de "agir pedagógico", é "um agir dialógico". Apresentam-se duas 
Trabalho Pedagógico na Escola

questões a essa afirmação do autor. Primeiro, que assim descrito, aproxima-se mais do conceito de prática, contra o qual se tem apresentado restrições. Os discursos referentes à educação escolar, não raramente, destacam a prática como atividade dessa instituição. Imbert pergunta-se “Há, ou não, lugar na escola para uma práxis?". A prática, para esse autor, é "um fazer" que acontece em um tempo e espaço com o objetivo de produzir "[...] um objeto (aprendizagens, saberes) e um sujeito-objeto (um escolar que recebe esse saber e sofre essas aprendizagens), mas que em nenhum momento é portador de uma perspectiva de autonomia" (Imbert, 2003, p. 15). Trata-se de prática, porque não está inclusa em um projeto pedagógico transformador, atem-se tão somente a aspectos isolados de um todo. Veja-se, por exemplo, uma prática escolar que objetiva mudar um hábito já instituído na escola. Descolada de um projeto maior, essa prática objetiva modificar em algum aspecto, e não na totalidade, as ações dos sujeitos. Por outro lado, se for considerada que a prática dos professores na instituição escolar é relacionada à produção de conhecimento, pode-se, então, entendê-la como práxis, pois o conhecimento está relacionado com o campo "[...] da atividade prática do homem, mas para garantir o êxito desta atividade ele deve relacionar-se necessariamente com a realidade objetiva que existe fora do homem e serve de objeto a essa atividade" (Kopnin, 1978, p. 125). Ao conhecer, o ser humano acaba por relacionar o real e o conhecido e, ao transformar seu modo de entender o mundo, também se transforma. Diferentemente ainda da práxis, a prática é instantânea, enquanto aquela “[...] significa uma tensão, uma visada, um projeto, que não se deixa fixar em termos determinados - um programa -, mas abre o campo de um processo indeterminado, não dedutível” (Imbert, 2003, p. 16). A autonomia, objetivo da práxis é, assim, um processo indeterminado, que tem início, mas pode tomar imprevistos rumos. Somente assim a práxis assume sua perspectiva de "[...] um fazer criador de realidades e de sentidos novos" (Imbert, 2003, p. 18). Por isso, tal processo está destinado ao "[...] imprevisto, para o não dedutível, para a criação, para a irrupção do novo" (Imbert, 2003, p. 20). Do ponto de vista dos sujeitos, a prática apenas os põe em interação, em busca do alcance de um objetivo, sem necessariamente implicá-los em um projeto coletivo, ou mesmo aliá-los na busca da consecução de um projeto transformador. A práxis, diferentemente, estabelece uma "[...] nova relação que une uns aos outros, cada elemento se vê transformando” (Imbert, 2003, p. 38).

Uma segunda restrição ao conceito apresentado por Dalbosco (2007) diz respeito ao fato de concentrar na dialogicidade a essencialidade do pedagógico. Acredita-se que a linguagem é condição para a produção dos sentidos acerca do mundo. Portanto, o trabalho pedagógico é todo o movimento que contribui para que a produção do conhecimento aconteça. Inclui os aspectos relativos ao espaço e ao tempo, aos sujeitos (e, por isso, aspectos sociais, políticos, culturais, econômicos), aos conhecimentos sobre Pedagogia (especialmente os relativos a como os sujeitos aprendem) e implica um projeto, uma ação coordenada que objetiva um fim. O próprio Dalbosco (2007, p. 77) completa o conceito, 
dizendo que não é “[...] resultado de uma consciência individual objetivadora que manipula e instrumentaliza objetos e pessoas, mas sim uma interação entre seres humanos mediada pelo diálogo vivido". Em contraposição, pode-se se afirmar que também o trabalho pedagógico na forma como foi descrito até agora não o é. Embora se defenda que é uma atividade que objetiva um fim, não se exclui a linguagem, meio para a interação entre sujeitos que produzem conhecimento. Entende-se que, assumindo a influência da obra de Habermas, Dalbosco descreve a ação dos seres humanos, centrada no que chama de ação comunicativa. Porém, tal descrição é convergente com o que se está criticando: o afastamento do trabalho pedagógico de sua centralidade, aproximando-o mais da noção de prática, quando, se acredita, deva ser práxis, ou seja, entender que o trabalho pedagógico, sendo trabalho, "[...] constitui-se numa categoria central e fundante, protoforma do ser social, porque possibilita a síntese entre teleologia e casualidade, que dá origem ao ser social" (Antunes, 2005, p. 156). A dialogicidade, então, é o ponto em comum. Na concepção de Dalbosco, é central. Na que se está defendendo, a linguagem, que permite o diálogo, é elemento integrante do trabalho pedagógico, articulada aos aspectos sociais, políticos, econômicos que se entremeiam na interlocução entre sujeitos.

Em suma, propõe-se que o trabalho dos professores, ao selecionar, organizar, planejar, realizar, avaliar continuamente, acompanhar, produzir conhecimento e estabelecer interações, só possa ser entendido como trabalho pedagógico, imerso em um contexto capitalista, no qual a força de trabalho dos professores é organizada pelas relações de emprego e no qual os sujeitos agem em condições sociais, políticas. Entretanto, ainda que esteja imerso nas relações capitalistas, o trabalho pedagógico, por suas características, apresenta possibilidades de o sujeito trabalhador ir além, projetar-se no seu trabalho de modo a confundir-se e movimentar-se humanamente com ele, uma vez que uma matéria-prima é a linguagem.

\section{Considerações Finais}

Com este texto, pretendeu-se apresentar aspectos que possam contribuir para elaborar sentidos, considerando o que já se conhece da produção acerca da categoria trabalho pedagógico e apresentado aspectos que permitam aprofundar esse conceito tão caro para as análises sobre educação escolar. Partiu-se das noções já elaboradas, ampliando-as, na medida em que se estabelecem critérios teórico-semânticos para analisá-la. Nesse viés, não se faz menção a trabalho educativo, por entendê-la mais ampla, atinente também ao social. Educar é possibilidade de qualquer sujeito, porém o trabalho pedagógico exige preparação, estudo, adentramento em uma ciência, entendimento sistematizado da educação, cabendo, portanto, aos professores, por suas características como profissionais. Também objetiva-se diferenciar trabalho pedagógico e prática pedagógica, por entender que esta é instantânea, menos apegada a um projeto, mais atinente ao momento. Contrariamente, o 
trabalho pedagógico exige uma leitura do real, uma proposição, uma validação da proposta e, ao longo do processo, uma avaliação. Por isso, é práxis.

Nesse contexto, práxis implica as relações sociais que os seres humanos estabelecem ao envidarem esforços em busca da manutenção de sua sobrevivência e está diretamente ligada à produção das condições materiais da vida humana, contribuindo também para a autoprodução do ser humano: "[...] o homem se faz e se transforma ao transformar o mundo" (Imbert, 2003, p. 13). É nesse sentido o desafio de um contínuo movimento humano "[...] podendo se abrir para um projeto histórico" (Imbert, 2003, p. 14). Sendo assim, práxis e prática são diferenciadas. Aquela é transformadora: “[...] não se trata de interpretar o mundo, mas de transformá-lo com vistas a ultrapassar a alienação humana” (Imbert, 2003, p. 14); esta, por sua vez, por não ter necessariamente uma elaboração revolucionária que possibilite ao sujeito comprometer-se indelevelmente com o seu mundo, pode restringir-se somente ao tempo presente, sendo instantânea e isolada de um projeto social. Assim distintas, a práxis contribui para a luta contra a reificação, entendida como “[...] o esquecimento do caráter histórico da vida social que conduz a aceitá-la como realidade quase natural, determinada e escapando à práxis humana" (Imbert, 2003, p. 14). A práxis, descolada do seu sentido revolucionário, não é práxis.

Os modos discursivos apresentados objetivaram sistematizar as formas como se combinam (tendo como campo empírico a pesquisa, cujos interlocutores foram professores, levando em conta a historicidade e vivência como professora na Educação Básica, no Ensino Superior):

a) os professores: I - como sujeitos autônomos de seu trabalho; II - como assujeitados em sua condição de empregados ou força de trabalho negociada e organizada por um contrato;

b) o trabalho pedagógico: I - como produção autônoma, mediante um projeto pedagógico individual e coletivo; II - como tarefa simplesmente cumprida em tempo e espaço determinados.

Combinadas, essas perspectivas revelam os modos como discursivamente se estabelecem as relações entre os sujeitos-trabalhadores e seu trabalho-trabalho pedagógico na escola.

Desse modo, acredita-se ter contribuído para ampliar a concepção de trabalho pedagógico e, com isso, ir além, buscando outros modos de caracterizá-lo. Esse é um objetivo a ser alcançado na medida em que, concomitantemente, se estuda e vivencia o trabalho como professores, o que permite ir revendo os sentidos e reelaborando-os na perspectiva de uma práxis pedagógica.

Recebido em 26 de abril de 2016 Aprovado em 21 de agosto de 2017 


\section{Notas}

1 Texto elaborado tendo por base de projeto desenvolvido com financiamento do Conselho Nacional de Desenvolvimento Científico e Tecnológico - CNPq e da Fundação de Apoio à Pesquisa no Estado do Rio Grande do Sul - FAPERGS.

2 Entende-se e, em consequência, defende-se as lutas da Didática para se estabelecer como fundamental área da Pedagogia. Entretanto, diferencia-se de Didática e trabalho pedagógico, estabelecendo entre eles uma relação de dependência. O trabalho, para ser pedagógico, necessita estar alicerçado nos princípios didáticos.

3 Trabalhador, no sentido lato, como aquele que realiza um trabalho e, ao fazê-lo, garante sua sobrevivência, produz historicidade como ser humano e social.

4 Cabe ressaltar, no intuito de evitar equívocos de compreensão, que a linguagem não substitui o trabalho, mas amplia. Não se está confundindo a materialidade da produção através do trabalho com o ideal resultante da produção da linguagem. Aquele é descrito nesta, mas não é substituído como produção humana por esta. Ou seja, somente a linguagem não transforma o ambiente, por isso, ela se coloca como possibilidade de descrever o trabalho.

5 Precarização, fragmentação e intensificação estão inter-relacionadas, sendo resultantes das condições relativas ao emprego que afetam o trabalho dos professores. A precarização diz respeito à falta de condições de trabalho. A fragmentação resulta da distribuição do trabalho no tempo, gerando a sensação de falta de tempo, falta de continuidade do projeto de trabalho. E a intensificação diz respeito ao acúmulo de funções, de atividades e compromissos, podendo gerar, até mesmo, autointensificação.

\section{Referências}

ALVES, Giovanni. Trabalho e Mundialização do Capital: a degradação do trabalho no capitalismo global. Londrina: Práxis, 1999.

AMORIM, Henrique. Trabalho Imaterial, Forças Produtivas e Transição nos Grundrisse de Karl Marx. In: CONFERÊNCIA INTERNACIONAL LA OBRA DE CARLOS MARXY LÓS DESAFIOS DE SIGLO XXI, 4., 2006, La Habana. Anais... La Habana, 2006. P. 01-08. Disponível em: <http://www.nodo50.org/cubasigloXXI/ congreso08/conf4_amorim.pdf $>$. Acesso em: abr. 2014.

ANTUNES, Ricardo. Os Sentidos do Trabalho: ensaio sobre a afirmação e a negação do trabalho. São Paulo: Boitempo Editorial, 2005.

BARDIN, Laurence. Análise de Conteúdo. Lisboa: Edições 70, 2011.

BASBAUM, Leôncio. Alienação e Humanismo. 3. ed. São Paulo: Símbolo, 1977. BOURDIEU, Pierre. O Poder Simbólico. 16. ed. Rio de Janeiro: Bertrand Brasil, 2012.

DALBOSCO, Claudio Almir. Pedagogia Filosófica: cercanias de um diálogo. São Paulo: Paulinas, 2007.

FERREIRA, Liliana Soares; HYPOLITO, Alvaro Moreira. Uma Análise sobre o Tema 'Trabalho' nos Eventos da Redestrado entre 2008 e 2011. Histedbr, Campinas, Universidade Estadual de Campinas, v. 13, n. 51, p. 27-41, 2013.

FERREIRA, Liliana Soares. Trabalho Pedagógico na Escola: sujeitos, tempo e conhecimentos. Curitiba: Editora CRV, 2017. 
FRIZZO, Giovanni Felipe Ernst. Trabalho Pedagógico: conceito central no trato do conhecimento da pesquisa em educação. Trabalho Necessário, Niterói, Universidade Federal Fluminense, v. 6, n. 6, p. 1-29, 2008.

FRIZZO, Giovanni Felipe Ernst; RIBAS, João Francisco Magno; FERREIRA, Liliana Soares. A Relação Trabalho-Educação na Organização do Trabalho Pedagógico da Escola Capitalista. Educação, Santa Maria, Universidade Federal de Santa Maria, v. 38, n. 3, set./dez. p. 553-564, 2013.

GRISCI, Carmem Ligia Iochins. Trabalho Imaterial. In: CATTANI, Antonio David; HOLZMANN, Lorena (Org.). Dicionário de Trabalho e Tecnologia. Porto Alegre: Editora da Universidade Federal do Rio Grande do Sul, 2006. P. 327-329. IMBERT, Francis. Para uma Práxis Pedagógica. Brasília: Plano Editora, 2003.

KOPNIN, Pável Vasílievich. A Dialética como Lógica e Teoria do Conhecimento. Rio de Janeiro: Civilização Brasileira, 1978.

MARX, Karl. O Capital: crítica da economia política. O processo de produção do capital. Rio de Janeiro: Civilização Brasileira, 2008.

MARX, Karl. Grundisse: manuscritos econômicos de 1857-1858: esboço para uma crítica da economia política. São Paulo: Boitempo; Rio de Janeiro: Editora da Universidade Federal do Rio de Janeiro, 2011.

PELBART, Peter Pal. Vida Capital: ensaios de biopolítica. São Paulo: Iluminuras, 2003.

SAVIANI, Dermeval. Escola e Democracia. São Paulo: Cortez, 1984.

SCHMIED-KOWARZIK, Wolfdietrich Pedagogia Dialética: de Aristóteles a Paulo Freire. São Paulo: Brasiliense, 1988.

VÁZQUEZ, Adolfo Sanchèz. Filosofia da Práxis. 2. ed., Rio de Janeiro: Paz e Terra. 1977.

VIGOTSKI, Lev Semenovich. Pensamento e Linguagem. São Paulo: Martins Fontes, 1996.

WERLE, Flávia Obino. Pós-Graduação e suas Interlocuções com a Educação Básica. Educação, Santa Maria, Universidade Federal de Santa Maria, v. 35, n. 3, p. 424-433, set./dez. 2012.

Liliana Soares Ferreira é doutora em Educação, professora do Programa de Pós-graduação em Educação da Universidade Federal de Santa Maria (UFSM) e do Programa de Pós-graduação em Educação Profissional e Tecnológica da UFSM.

E-mail: anaililferreira@yahoo.com.br 